\title{
Cardiovascular responses to microinjections of GABA or anesthetics into the rostral ventrolateral medulla of conscious and anesthetized rats
}

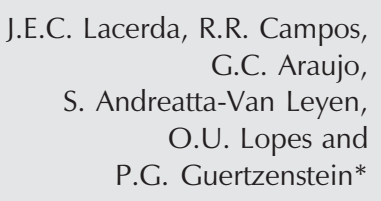

Departamento de Fisiologia, Escola Paulista de Medicina, Universidade Federal de São Paulo, São Paulo, SP, Brasil

\section{Correspondence \\ R.R. Campos \\ Departamento de Fisiologia \\ EPM, UNIFESP \\ Rua Botucatu, 862 \\ 04023-060 São Paulo, SP \\ Brasil \\ Fax: +55-11-5573-7820 \\ E-mail: campos@fcr.epm.br \\ *Prof. P.G. Guertzenstein died on July 17,1994 . This research, in \\ addition to having his direct \\ participation, is a tribute to \\ a person who was a pioneer in \\ the study of the role of the \\ ventrolateral medulla in \\ cardiovascular regulation.}

Research supported by FAPESP and CAPES.

Received June 5, 2002

Accepted May 9, 2003

\section{Abstract}

The rostral ventrolateral medulla (RVLM) contains neurons involved in tonic and reflex control of arterial pressure. We describe the effects of gamma-aminobutyric acid (GABA) and anesthetics injected into the RVLM of conscious and urethane $(1.2 \mathrm{~g} / \mathrm{kg}, i v)$ anesthetized Wistar rats (300-350 g). In conscious rats, bilateral microinjection of GABA (50 nmol/200 nl) induced a small but significant decrease in blood pressure (from $130 \pm 3.6$ to $110 \pm 5.6 \mathrm{mmHg}, \mathrm{N}=7$ ). A similar response was observed with sodium pentobarbital microinjection (24 $\mathrm{nmol} / 200 \mathrm{nl}$ ). However, in the same animals, the fall in blood pressure induced by GABA (from $121 \pm 8.9$ to $76 \pm 8.8 \mathrm{mmHg}, \mathrm{N}=7$ ) or pentobarbital (from $118 \pm 4.5$ to $57 \pm 11.3 \mathrm{mmHg}, \mathrm{N}=6$ ) was significantly increased after urethane anesthesia. In contrast, there was no difference between conscious (from $117 \pm 4.1$ to $92 \pm 5.9 \mathrm{mmHg}$, $\mathrm{N}=7$ ) and anesthetized rats (from $123 \pm 6.9$ to $87 \pm 8.7 \mathrm{mmHg}$, $\mathrm{N}=7$ ) when lidocaine $(34 \mathrm{nmol} / 200 \mathrm{nl})$ was microinjected into the RVLM. The heart rate variations were not consistent and only eventually reached significance in conscious or anesthetized rats. The right position of pipettes was confirmed by histology and glutamate microinjection into the RVLM. These findings suggest that in conscious animals the RVLM, in association with the other sympathetic premotor neurons, is responsible for the maintenance of sympathetic vasomotor tone during bilateral RVLM inhibition. Activity of one or more of these premotor neurons outside the RVLM can compensate for the effects of RVLM inhibition. In addition, the effects of lidocaine suggest that fibers passing through the RVLM are involved in the maintenance of blood pressure in conscious animals during RVLM inhibition.
Key words

- Vasomotor tone

- Ventrolateral medulla

- RVLM

- GABA

- Conscious rats 


\section{Introduction}

A turning point in our knowledge of the autonomic nervous system control of arterial blood pressure (BP) was the identification of the ventrolateral medulla and the demonstration of its key role in BP maintenance and reflex cardiovascular control (1-3).

Two distinct areas have been identified within the ventrolateral medulla: the rostral ventrolateral medulla (RVLM), responsible for maintaining the tonic excitation of sympathetic preganglionic neurons $(4,5)$, and the caudal ventrolateral medulla, a depressor area clearly involved in the reflex regulation of BP $(2,3)$. Recently, a third area in a region known as the caudal pressor area has been shown to play an important role in generating sympathetic vasomotor tone in the rat. A significant proportion of tonic activity in RVLM sympathetic premotor neurons is driven by neurons in the caudal pressor area, at least in anesthetized animals $(6,7)$.

The RVLM is a pressor area and one of the sympathetic premotor neurons (8). In the rat, the RVLM extends from 1.0 to $2.5 \mathrm{~mm}$ rostral to the median rootlet of the XII nerve and 1.5-2.0 mm lateral to the midline (9). There is a large body of evidence showing that the functional integrity of the RVLM is essential for the maintenance of the basal sympathetic vasomotor tone. Electrolytic lesion or chemical inactivation of RVLM neurons by inhibitory amino acids such as glycine or gamma-aminobutyric acid (GABA) results in a fall of BP similar to that usually obtained in acute spinal animals (4,10-12). However, these studies were performed on anesthetized animals, a condition that may be a limiting factor in the interpretation and analysis of the results. For example, glutamate microinjections into the RVLM in conscious animals cause a larger increase in BP compared to anesthetized rats (13). Unilateral or bilateral microinjection of glycine into the RVLM decreases BP in anesthetized rats, whereas in conscious animals the same procedure causes an opposite effect (14). There is no comparative study regarding the cardiovascular effects of different inhibitory drugs into the RVLM in conscious and anesthetized rats.

The aim of the present study was to investigate the cardiovascular effects of microinjection of GABA, sodium pentobarbital and lidocaine into the RVLM of conscious animals and to compare the results with those obtained for urethane-anesthetized rats.

\section{Material and Methods}

\section{General procedures}

Male Wistar rats weighing 300-350 g were used. The animal experimentation Ethics Committee of the Universidade Federal de São Paulo approved the experiments. For the surgical procedure, rats were anesthetized with sodium pentobarbital $(40 \mathrm{mg} / \mathrm{kg}$, $i p$ ), and the right femoral vein and artery were cannulated and dorsally exteriorized for drug infusion and for BP recording using a transducer (Statham P23 Db, Quincy, MA, USA) connected to a Beckman R511A recorder. Mean arterial pressure (MAP) was obtained by filtering the BP signal in a second channel, and heart rate (HR) was recorded with a cardiotachometer (Beckman 9857B, Schiller Park, IL, USA) triggered by the pulse wave in a third channel. Body temperature was maintained at $37 \pm 0.5^{\circ} \mathrm{C}$ by a heating table.

Animals were placed prone in a stereotaxic apparatus with the bite bar $5 \mathrm{~mm}$ below the interaural line. The lambda was taken as a landmark for the stereotaxic coordinates.

\section{Cannula implantation into the RVLM}

The method used for conscious animals was a development of the method already used in our laboratory for anesthetized acute experiments $(6,15)$. Two occipital holes were 
bilaterally drilled to allow penetration of the guide cannulas. Two separate electrode manipulators were used in the stereotaxic frame with independent movements, allowing distinct rostral, caudal and lateral measurements on each side. The electrode carriers were bent $8^{\circ}$ backwards. A stainless steel tube (1.5-mm outer diameter (OD) x $15 \mathrm{~mm}$ in length) was fixed on the side of an electrode holder in order to contain and allow displacement of the support system of the guide cannula.

Since the guide cannulas were very small (they were made from two coupled needles, -0.6- and 0.9-mm OD and 11 and $10 \mathrm{~mm}$ in length) their handling was facilitated by coupling them to a support cannula made with the same needles, but having a length of 26 $\mathrm{mm}$, inserted into the stainless steel tube mentioned above.

A stainless steel micropipette $(\mathrm{OD}=0.3$ $\mathrm{mm}$ ) was placed inside the set of the support and guide cannulas. The length of the micropipettes and of the guide cannulas was adjusted to allow only the micropipettes to be inserted into the brain tissue. The guide cannula was then directed at the desired stereotaxic position $(\mathrm{AP}=-1.8 \mathrm{~mm}$ posterior to the lambda and $\mathrm{L}=1.6 \mathrm{~mm}$ lateral to the parietal suture) according to the atlas of Paxinos and Watson (16). Vertical positioning was obtained by slowly lowering both the micropipette and the set of supporting and guide cannulas until a slight displacement between them was observed.

To confirm the position of the micropipette, L-glutamate $(6 \mathrm{nmol} / 200 \mathrm{nl})$ was injected into the RVLM. A hypertensive response of at least $30 \mathrm{mmHg}$ was taken as the positive control. No more than two attempts were made on each side. Once the response was confirmed, the guide cannulas were kept in place with acrylic polymer and the support systems were withdrawn. Two screws were placed $+2 \mathrm{~mm}$ from the lambdoid sutures for further stabilization of the guide cannulas. Finally, the cannulas were sur- rounded with a ring-like crown structure in order to protect the cannulas from contact with the animal's paw.

The animals were allowed to recover from surgery for at least $24 \mathrm{~h}$. On the day of the experiments, they were kept in their individual cages, and basal recordings of $\mathrm{BP}$ and HR were obtained for at least $30 \mathrm{~min}$ from conscious rats.

\section{Drug microinjections}

Drugs were microinjected into the RVLM through micropipettes placed inside guide cannulas and connected to Hamilton (701) microsyringes fixed in a manual injector. The positions of the micropipettes were determined previously as described above. Only one drug was tested on each animal by a single bilateral microinjection. Microinjections consisted of $50 \mathrm{nmol} \mathrm{GABA}, 24 \mathrm{nmol}$ sodium pentobarbital or $34 \mathrm{nmol}$ lidocaine chlorhydrate diluted in $200 \mathrm{nl}$ of physiological saline and the duration of microinjection for each side was approximately $10 \mathrm{~s}$. This relatively large volume was used to be certain that the entire RVLM region was reached by the drugs. The $\mathrm{pH}$ of the solutions was adjusted to 7.4. These drugs and doses were selected because they were used extensively in previous studies of the role of the ventrolateral medulla in the maintenance of BP in rats (17).

After $24 \mathrm{~h}$ of recovery from the microinjection, the animals were anesthetized slowly with urethane $(1.2 \mathrm{~g} / \mathrm{kg}, i v)$ and the same procedure was repeated for microinjection of drugs. The same drug used in the conscious condition was microinjected again into the same animal after anesthesia.

\section{Histology}

At the end of each experiment, $200 \mathrm{nl}$ of $2 \%$ Evans blue dye was injected into the ventromedullary sites. Animals were sacrificed with an overdose of urethane and the 
Figure 1. Typical bilateral microinjection sites into the rostral ventrolateral medulla evaluated by $200 \mathrm{nl}$ of Evans blue diffusion (A). In $B$, a schematic representation of the medulla. Amb, nucleus ambiguus; CST, corticospinal tract; ION, inferior olivary nucleus; NTS, nucleus of the tractus solitarii; STN, spinal trigeminal nucleus.

Figure 2. Effects of bilateral microinjection of gamma-aminobutyric acid (GABA, $50 \mathrm{nmol} / 200$ nl) into the RVLM on the mean arterial pressure (MAP) and heart rate (HR) of conscious (left, $\mathrm{N}=$ 7) or anesthetized (right, $\mathrm{N}=7$ ) rats. ${ }^{*} P<0.05$ compared to respective control (Student paired t-test) brainstem was removed and fixed in 10\% formaldehyde for histological analysis (6). The injection sites, as indicated by dye diffusion, were ovoid-shaped ranging from 1.5 to $2.0 \mathrm{~mm}$ in the rostrocaudal direction and from 0.8 to $1.2 \mathrm{~mm}$ on the mediolateral axis, and extended 0.5 to $0.8 \mathrm{~mm}$ dorsal to the ventral surface. A characteristic injection site is shown in Figure 1. A significant change
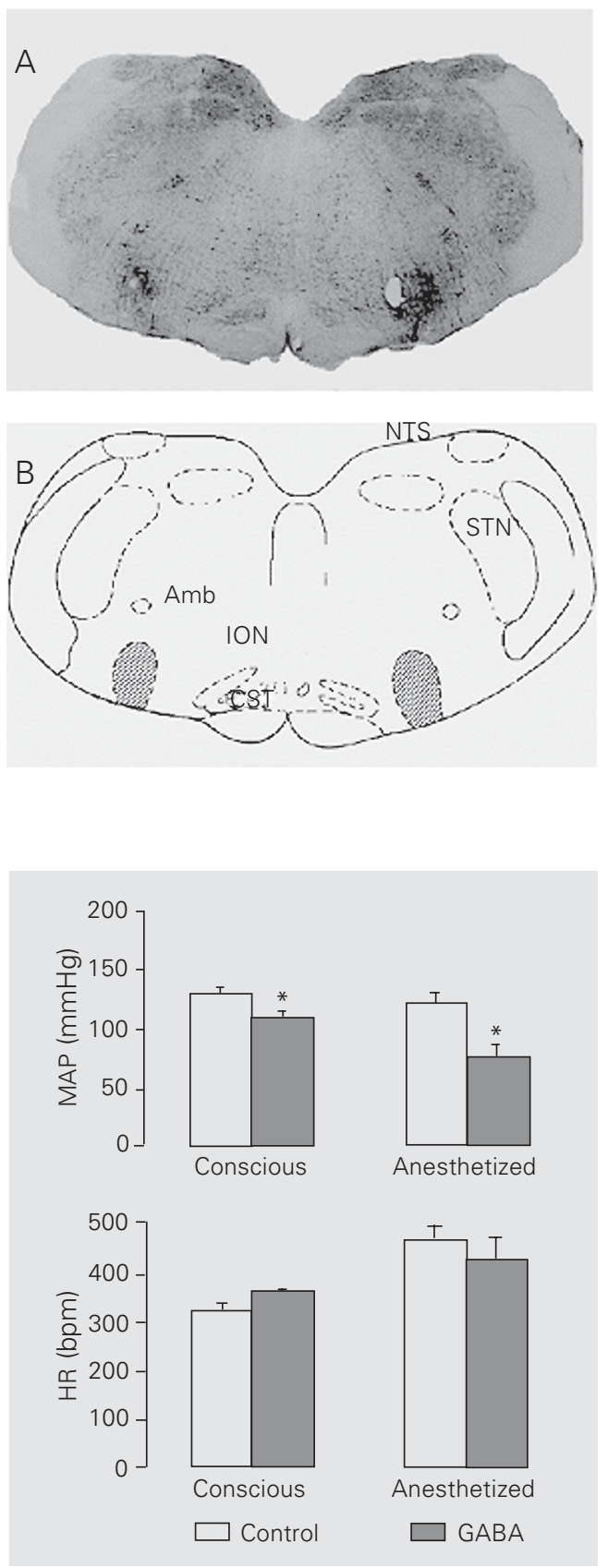

in $\mathrm{BP}$ in conscious or anesthetized animals was observed only when the dye was deposited ventral to the nucleus ambiguus and lateral to the inferior olivary nucleus. When the drugs were injected outside this region no response was obtained. The injection sites were plotted on a map according to the atlas of Paxinos and Watson (16).

\section{Statistical analysis}

All data are reported as means \pm SEM. The significance of changes in MAP or HR following microinjection was determined within each group by the Student paired $t$ test. The cardiovascular responses to microinjection of drugs into the RVLM of conscious or anesthetized rats were assessed by analysis of variance (ANOVA) followed by the Student-Newman-Keuls test. Differences were considered significant for a $\mathrm{P}$ value $<0.05$ in relation to the basal condition.

\section{Results}

\section{Effects of bilateral microinjection of GABA into the RVLM}

As shown in Figure 2, bilateral microinjection of GABA into the RVLM provoked a decrease in BP and tachycardia in conscious animals. However, in anesthetized animals, bilateral injection of GABA into this area produced a more intense hypotension, as shown in Figure 2. In a group of 7 animals, bilateral injection of GABA into the RVLM of conscious animals significantly reduced MAP (control: $130 \pm 3.6$; after GABA: $110 \pm$ $5.6 \mathrm{mmHg} ; \mathrm{P}<0.05)$ with a nonsignificant change in HR (control: $326 \pm 12.4$; after GABA: $358 \pm 8.6 \mathrm{bpm}$; Figure 2). The response started during the microinjection, peaked at $2 \mathrm{~min}$ and remained below resting level for $5.5 \pm 1.0 \mathrm{~min}$. When GABA was microinjected into the RVLM in anesthetized animals $(\mathrm{N}=7)$, a significant and prominent decrease in MAP was observed (con- 
trol: $121 \pm 8.9$; after GABA: $76 \pm 8.8 \mathrm{mmHg}$; $\mathrm{P}<0.05)$ but no significant change in $\mathrm{HR}$ was observed (control: $469 \pm 24.7$; after GABA: $426 \pm 46.6$ bpm; Figure 2). The decrease in MAP in response to GABA observed in anesthetized animals was significantly greater than in the conscious condition. The response started $30 \mathrm{~s}$ after the end of the microinjection, peaked at $2 \mathrm{~min}$ and remained below resting level for approximately $10 \mathrm{~min}$.

\section{Effects of bilateral microinjection of sodium pentobarbital into the RVLM}

Bilateral microinjection into conscious animals produced only a small, but significant, fall in MAP not associated with a significant variation in HR, although there was a tendency to tachycardia (control MAP: $131 \pm 4.0$; after the drug: $123 \pm 4.9 \mathrm{mmHg}$; control HR: $337 \pm 32$; after the drug: $368 \pm$ $36.4 \mathrm{bpm})$. In contrast, in anesthetized animals, the decrease in BP was significantly larger (control BP: $118 \pm 4.5$; after the drug: $57 \pm 11.3 \mathrm{mmHg}, \mathrm{N}=6$ ). The response was accompanied by a significant change in HR (Figure 3).

Effects of bilateral microinjection of lidocaine chlorhydrate into the RVLM

The same procedure was used with microinjections of lidocaine chlorhydrate into the RVLM performed in conscious $(\mathrm{N}=7)$ as well as in anesthetized animals $(\mathrm{N}=7)$. The fall in BP was similar in anesthetized and conscious animals (control MAP of conscious animals: $117 \pm 4.1$; after lidocaine: 92 $\pm 5.9 \mathrm{mmHg}$; control MAP of anesthetized animals: $123 \pm 6.9$; after lidocaine: $87 \pm 8.7$ $\mathrm{mmHg}$ ). Bilateral microinjection into conscious animals produced a significant increase in HR (control: $315 \pm 18.1$; after lidocaine: $380 \pm 18.0 \mathrm{bpm}$ ), whereas no change in HR was observed in the anesthetized condition (Figure 4).
Effects of bilateral microinjection of saline into the RVLM

Control injections of saline into conscious animals produced a small and nonsignificant increase in MAP (control: $122 \pm 3.8$; after saline: $129 \pm 5.8 \mathrm{mmHg}$ ) with no change in HR (control: $372 \pm 9.8$; after saline: $364 \pm$

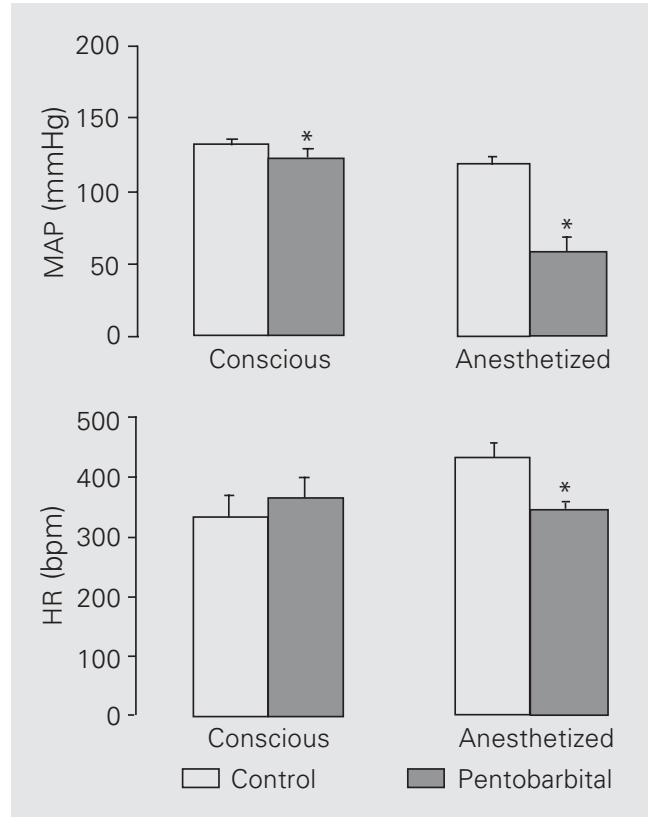

Figure 3. Effects of bilateral microinjection of sodium pentobarbital $(24 \mathrm{nmol} / 200 \mathrm{nl})$ into the RVLM on the mean arterial pressure (MAP) and heart rate (HR) of conscious (left, $N=6$ ) or anesthetized (right, $\mathrm{N}=6$ ) rats. ${ }^{*} \mathrm{P}<0.05$ compared to respective control (Student paired $t$-test).

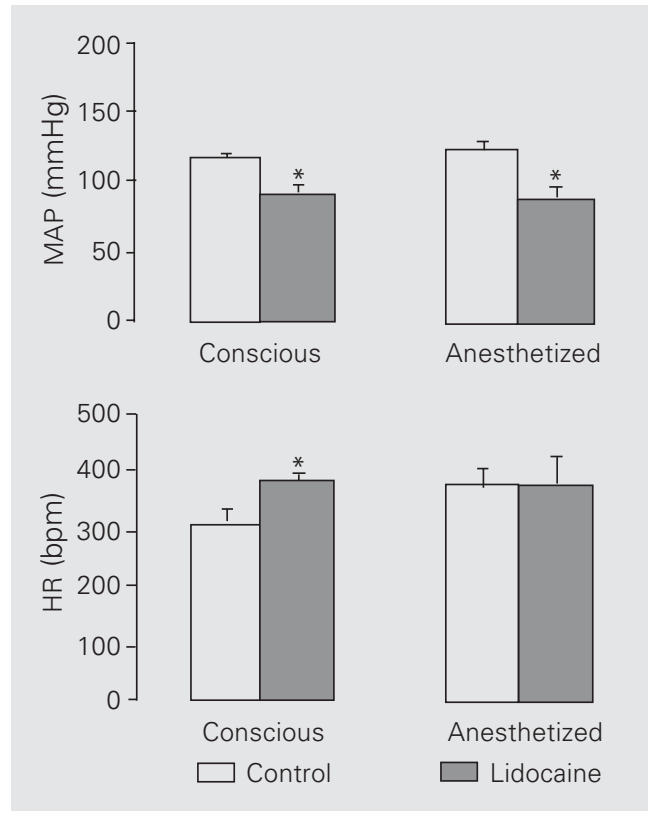

Figure 4. Effects of bilateral microinjection of lidocaine (34 $\mathrm{nmol} / 200 \mathrm{nl}$ ) into the RVLM on the mean arterial pressure (MAP) and heart rate (HR) of conscious (left, $\mathrm{N}=7$ ) or anesthetized (right, $\mathrm{N}=7$ ) rats. ${ }^{*} \mathrm{P}<$ 0.05 compared to respective control (Student paired $t$-test). 
Figure 5. Effects of bilateral microinjection of saline $(0.9 \%, 200$ nl) into the RVLM on the mean arterial pressure (MAP) and heart rate $(H R$ ) of conscious (left, $N=$ 6) and anesthetized (right, $N=6$ ) rats.

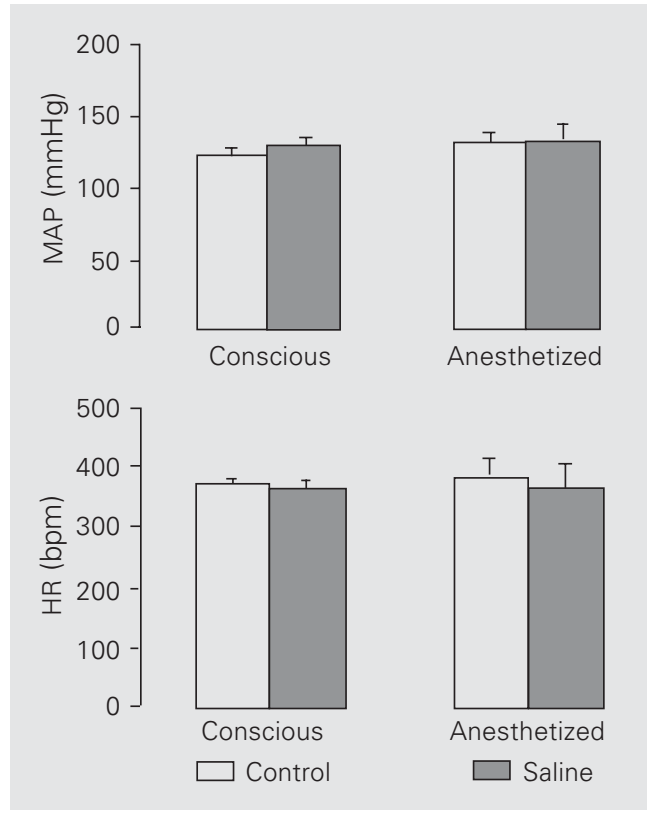

10.7 bpm, $N=6$ ). Similar results were obtained in anesthetized animals, with the microinjection of saline producing a discrete increase in MAP (control: $130 \pm 6.4$; after saline: $134 \pm 8.9 \mathrm{mmHg}$ ) but no significant change in HR (control: $387 \pm 32$; after saline: $365 \pm 43.6 \mathrm{bpm}, \mathrm{N}=6$ ), as shown in Figure 5.

\section{Discussion}

The major new finding of the present study was the demonstration that: 1) the fall in BP in response to microinjection of GABA and pentobarbital into the RVLM was greater in anesthetized than in conscious animals, and 2) there was no difference between groups when lidocaine was injected.

Previous studies on different species have shown that the integrity of the RVLM is essential for the maintenance of BP and for the reflex control of the cardiovascular system $(18,19)$. RVLM inhibition by GABA produced a fall in BP similar to that observed after acute spinal cord transection. However, the cited studies were carried out on animals anesthetized with urethane, $\alpha$-chloralose or sodium pentobarbital (20-22), drugs with central and peripheral effects that might directly or indirectly modify the cardiovascular responses to RVLM inhibition. Cochrane and Nathan (23), for example, showed that the hypotension produced by RVLM lesion in rats is dependent on the anesthesia. They showed that the persistent fall in MAP after RVLM lesion appeared only in animals anesthetized with urethane, whereas in animals anesthetized with sodium pentobarbital or $\alpha$-chloralose only a transient hypotension was observed. These studies with electrolytic lesions agree with our results with pharmacological inhibition, which show that the cardiovascular effects of RVLM inactivation are also affected by the anesthesia condition.

In the present study we found that the fall in BP caused by RVLM inhibition with GABA or pentobarbital was less intensive in conscious than in anesthetized rats. Araujo et al. (14) also found that the depressor response to glycine into the RVLM was observed only when low doses of the drug were injected and, in this case, the fall in BP was also more marked in anesthetized rats. This result supports the view that the actions of inhibitory amino acids into the RVLM are clearly influenced by anesthesia.

Urethane might either directly or indirectly affect the magnitude of the cardiovascular responses mediated by drugs microinjected into the RVLM. It has been demonstrated that urethane produces hormonal or biochemical changes that can interfere with the cardiovascular responses. Some responses involving pharmacological stimulation of adrenoceptors are affected by urethane (24). Since these receptors are involved in the responses mediated by the RVLM we may postulate that the central or peripheral actions of urethane on adrenoceptors can interfere with actions mediated by premotor neurons of the ventrolateral medulla.

Fontes et al. (25) showed that microinjection of both AT1 and AT2 ligands into the RVLM in conscious rats produced pressor 
effects at doses that did not change BP in anesthetized rats, another example of differential responses by conscious and anesthetized rats.

It is possible that in conscious animals other areas of the nervous system are capable of maintaining BP during RVLM inhibition. Until a short time ago the RVLM was recognized as the only area in the brainstem in which pharmacological inhibition could produce a decrease in BP. More recently, however, a tonic vasomotor activity was demonstrated in the parabrachial nucleus (26), the pontine reticular formation (27), the paraventricular nucleus of hypothalamus and the caudalmost ventrolateral medulla, the caudal pressor area (15).

In studies with cats under chloralose anesthesia, Feldberg and Guertzenstein (1) demonstrated that in the medullary-spinal transition an area (caudal pressor area) appears to maintain BP. These investigators demonstrated that during surgical anesthesia with chloralose the stimulation of this area by leptazol produced a decrease in BP. In contrast, when the same animals were profoundly anesthetized, an increase in BP was observed. Machado and Bonagamba (28) showed that glutamate microinjection into the nucleus tractus solitarii of rats anesthetized with urethane or chloralose produces a fall in BP. However, in conscious animals, a dose-dependent increase in BP was observed in response to glutamate. These data emphasize the influence of anesthesia on the cardiovascular responses mediated by drug microinjections in specific regions of the brainstem involved in cardiovascular regulation.

In the same type of experiment, Bachelard et al. (13) demonstrated that the cardiovascular responses to microinjection of L-glutamate into the RVLM are more prominent in conscious animals than in animals anesthetized with urethane.

One explanation for the observation of a different intensity in the cardiovascular response to microinjection of GABA and pen- tobarbital into the RVLM of conscious and anesthetized animals could be that in conscious animals behavioral effects may cause secondary cardiovascular alterations that may mask the actions of these drugs. However, this possibility seems to be remote since no behavioral alterations were observed in response to microinjections of GABA, pentobarbital, lidocaine or saline into the RVLM of conscious animals. In addition, saline microinjection into the RVLM did not change BP or HR. We cannot exclude, however, the possibility that in non-anesthetized animals the baroreceptor reflex is more effective in compensating changes in BP during RVLM inhibition. Sakima et al. (29), for example, showed that glutamate microinjection into the RVLM of conscious rats caused a decrease in HR but no change in anesthetized animals.

Another point is the possible influence of respiratory alterations masking cardiovascular responses in conscious animals. Vehicle injections into the RVLM, for example, did not change $\mathrm{BP}$ or $\mathrm{HR}$, suggesting that if there is any respiratory component in the cardiovascular responses mediated by microinjections into the RVLM in conscious rats it is probably not important. In addition, the respiratory neurons in the ventrolateral medulla are close but located more dorsally than the premotor RVLM neurons (30). In this case, our microinjections were located ventrally in relation to the respiratory group, probably mainly reaching the cardiovascular neurons. However, only new experiments can solve this question.

The only drug that caused the same effect on BP in both conscious and anesthetized rats was lidocaine. It is possible that this agent was more effective than GABA or pentobarbital because of its action on both neurons and fibers of passage.

Finally, it is possible that in conscious animals the RVLM in association with other areas of the brain is responsible for the maintenance of vasomotor tone and sympathetic 
activity. We may hypothesize that during RVLM inhibition other areas outside the RVLM may take on its role in the maintenance of arterial pressure in conscious animals. The fact that lidocaine injection into the RVLM causes a similar fall in BP in conscious and anesthetized rats suggests that fibers from other nuclei passing through the RVLM are involved in the maintenance of $\mathrm{BP}$ in conscious animals.

\section{References}

1. Feldberg W \& Guertzenstein PG (1986). Blood pressure effects of leptazol applied to the ventral surface of the brain stem of cats. Journal of Physiology, 372: 445-456.

2. Feldberg W \& Guertzenstein PG (1976). Vasodepressor effects obtained by drugs acting on the ventral surface of the brain stem. Journal of Physiology, 258: 337-355.

3. Guertzenstein PG \& Lopes OU (1984). Cardiovascular responses evoked from the nicotine sensitive area on the ventral surface of the medulla oblongata in the cat. Journal of Physiology, 347: 345360 .

4. Guertzenstein PG \& Silver A (1974). Fall in blood pressure produced from discrete regions of the ventral surface of the medulla by glycine and lesions. Journal of Physiology, 242: 489-503.

5. Calaresu FR \& Yardley CP (1988). Medullary basal sympathetic tone. Annual Review of Physiology, 50: 511-524.

6. Possas OS, Campos Jr RR, Cravo SL, Lopes OU \& Guertzenstein PG (1994). A fall in arterial blood pressure produced by inhibition of the caudalmost ventrolateral medulla: the caudal pressor area. Journal of the Autonomic Nervous System, 49: 235-245.

7. Campos RR \& McAllen RM (1999). Tonic drive to sympathetic premotor neurons of rostral ventrolateral medulla from caudal pressor area neurons. American Journal of Physiology, 276: R1209R1213.

8. Amendt K, Czachurski J, Dembwsky K \& Seller H (1978). Neurons within the "chemosensitive area" on the ventral surface of the brainstem which project to the intermediolateral column. Pflüger's Archiv, 375: 289-292.

9. Benarroch EE, Granata AR, Ruggiero DA, Park DH \& Reis DJ (1986). Neurons of $\mathrm{C} 1$ area mediate cardiovascular responses initiated from ventral medullary surface. American Journal of Physiology, 250: R932-R945.

10. Dampney RAL \& Moon EA (1980). Role of ventrolateral medulla in vasomotor response to cerebral ischemia. American Journal of Physiology, 239: H349-H358.

11. Guertzenstein PG (1973). Blood pressure effects obtained by drugs applied to the ventral surface of the brain stem. Journal of Physiology, 229: 395-408.

12. Granata AR, Ruggiero DA, Park DH, Joh TH \& Reis DJ (1983). Lesions of epinephrine neurons in the ventrolateral medulla abolish the vasopressor components of baroreflex and cardiopulmonary reflex. Hypertension, 5: V80-V84.

13. Bachelard H, Gardiner SM \& Bennett $T$ (1990). Cardiovascular responses elicited by chemical stimulation of the rostral ventrolateral medulla in conscious, unrestrained rats. Journal of the Autonomic Nervous System, 31: 185-190.

14. Araujo GC, Lopes OU \& Campos RR (1999). Importance of glycinergic and glutamatergic synapses within the rostral ventrolateral medulla for blood pressure regulation in conscious rats. Hypertension, 34 (Part 2): 752-755.
15. Campos Jr RR, Possas OS, Cravo SL, Lopes OU \& Guertzenstein PG (1994). Putative pathways involved in cardiovascular responses evoked from the caudal pressor area. Brazilian Journal of Medical and Biological Research, 27: 2467-2479.

16. Paxinos G \& Watson C (1986). The Rat Brain in Stereotaxic Coordinates. 2nd edn. Academic Press Ltd., San Diego, CA, USA.

17. Dampney RAL (1994). The subretrofacial vasomotor nucleus: anatomical, chemical and pharmacological properties and role in cardiovascular regulation. Progress in Neurobiology, 42: 197-227.

18. McAllen RM, Neil JJ \& Loewy AD (1982). Effects of kainic acid applied to the ventral surface of the medulla oblongata on vasomotor tone, the baroreceptor reflex and hypothalamic autonomic responses. Brain Research, 683: 65-76.

19. Granata AR, Ruggiero DA, Park DH, Joh TH \& Reis DJ (1985). Brain stem area with $\mathrm{C} 1$ epinephrine neurons mediates baroreflex vasodepressor responses. American Journal of Physiology, 248: H547H567.

20. Keeler JR, Shults CW, Chase TN \& Helke CJ (1984). The ventral surface of the medulla in the rat: Pharmacologic and autoradiographic localization of GABA-induced cardiovascular effects. Brain Research, 297: 217-224.

21. Ross CA, Ruggiero DA, Park DH, Joh TH, Sved AF, FernandezPardal J, Saavedra JM \& Reis DJ (1984). Tonic vasomotor control by the rostral ventrolateral medulla: effect of electrical or chemical stimulation of the area containing $\mathrm{C} 1$ adrenaline neurons on arterial pressure, heart rate, and plasma catecholamines and vasopressin. Journal of Neuroscience, 4: 474-494.

22. Stornetta RL, Guyenet PG \& McCarty RC (1987). Autonomic nervous system control of heart rate during baroreceptor activation in conscious and anesthetized rats. Journal of the Autonomic Nervous System, 20: 121-127.

23. Cochrane $K L$ \& Nathan MA (1989). Normotension in conscious rats after placement of bilateral electrolytic lesions in the rostral ventrolateral medulla. Journal of the Autonomic Nervous System, 26: 199211.

24. Armstrong JM, Lefevre-Borg F, Scatton B \& Cavero I (1982). Urethane inhibits cardiovascular responses mediated by the stimulation of alpha-2 adrenoceptors in the rat. Journal of Pharmacology and Experimental Therapeutics, 223: 524-535.

25. Fontes MA, Pinge MC, Naves V, Campagnole-Santos MJ, Lopes OU, Kosla MC \& Santos RA (1997). Cardiovascular effects produced by microinjection of angiotensins and angiotensin antagonists into the ventrolateral medulla of freely moving rats. Brain Research, 750: 305-310.

26. Paton JFR \& Spyer KM (1990). Brain stem regions mediating the cardiovascular responses elicited from the posterior cerebellar cortex in the rabbit. Journal of Physiology, 427: 533-552.

27. Hayes K \& Weaver LC (1992). Tonic sympathetic excitation and vasomotor control from pontine reticular neurons. American Jour- 
nal of Physiology, 263: H1567-H1575.

28. Machado BH \& Bonagamba LG (1992). Microinjection of L-glutamate into the nucleus tractus solitarii increases arterial pressure in conscious rats. Brain Research, 576: 131-138.

29. Sakima A, Yamazato M, Sesoko S, Muratani H \& Fukiyama K (2000). Cardiovascular and sympathetic effects of L-glutamate and glycine injected into the rostral ventrolateral medulla of conscious rats. Hypertension Research, 23: 633-641.

30. Dobbins EG \& Feldman JL (1994). Brainstem network controlling descending drive to phrenic motoneurons in rat. Journal of Comparative Neurology, 347: 584-593 